\title{
O edifício, instrumento do evento: uma problemática (1)
}

Gérard Monnier*

\section{Resumo}

A relação instrumental do edifício com o conceito de evento é diversificada e complexa. O edifício pode ser ou o agente de um evento histórico, ou um evento reconhecido como tal na história da vida das formas, isto é, no campo da arquitetura. Eu proponho acrescentar uma terceira categoria, a do edifício-instrumento de uma criação cultural reconhecida como evento. Os edifícios, em suas relações com o evento, foram durante muito tempo instrumentos da representação simbólica e suportes da informação. O rápido desenvolvimento da indústria do entretenimento abre um novo capítulo: o edifício pode tornar-se a engrenagem principal de uma máquina de divertir através dos eventos.

Palavras-chave: Teoria da Recepção. Representação arquitetônica. Valores culturais (Riegl).

\section{The building as an instrument of the event}

\begin{abstract}
The instrumental relationship between the building and the concept of event is diversified and complex. Either the building is the agent of a historical event or an event in itself, recognized as such within the history of the life of forms, that is, the field of architecture. I propose to include a third category: that of the building as instrument of a cultural creation acknowledged as event. The buildings, in their relationship with the event, have long been instruments of symbolic representation and information supports. The rapid development of entertaining industries opens a new chapter: the building can become the main machine for entertainment through events.
\end{abstract}

Key-words: Theory of Reception. Architectural representation. Cultural values (Riegl). 


\section{Introdução}

Formulo a hipótese que a relação instrumental do edifício com o conceito de evento (2) é diversificada e complexa (3). Uma coisa é o edifício ser o agente de um evento histórico, outra é o edifício ser um evento reconhecido como tal na história da vida das formas, no caso, no campo arquitetônico. Aplicando ao edifício-evento as categorias definidas por Riegl para os monumentos, Henri Focillon, em sua época, já havia formulado essa repartição do evento arquitetônico em duas entidades distintas (4). Proponho acrescentar uma terceira categoria, a do edifício-instrumento de uma criação cultural forte, reconhecida como evento. Ocorrerá que, para um dado edifício, o pertencimento a mais de uma dessas categorias será efetivo; desse modo, o Palácio dos Papas foi concomitantemente o instrumento do papado em Avignon e o instrumento de uma série de eventos na criação teatral do século 20 (5). Essas superposições, como se sabe, eram já admitidas por Riegl para as categorias de monumentos.

\section{0 edifício, instrumento do evento histórico}

O edifício e o evento localizado. A maior parte dos eventos que a crônica e a história mencionam são localizados; a ponto de o nome do lugar designar o evento e é ele que entra na legenda dos séculos: desse modo, Roncevaux, Azincourt, Waterloo, Trafalgar, Auschwitz, Cabo Canaveral, assim como a sagração dos reis da França em Reims, os tratados de Viena e de Versalhes. Escapam dessa localização apenas os episódios acidentais ocorridos em alto mar (o naufrágio do La Méduse, o do Titanic) e os desaparecimentos de aviões, ainda que os naufrágios perto da costa sejam localizados por intermédio das marés negras e dos danos locais que elas provocam. Ocorre que essa localização do evento histórico se encerra na designação de um lugar preciso - a Festa da Federação no Campo de Marte - e freqüentemente num edifício, a ponto de ele ser mencionado nos termos que designam o evento: o juramento do Jeu de Paume (6); a tragédia de Vel d'Hiv (7); a do metrô de Charonne (8); o muro de Berlin.

O edifício pode ser banal e sua identificação aproximativa, mas se torna monumento de fato (9); fica então disponível para fixar a comemoração, sob a forma de manifestações, de representações. Por vezes, a comemoração do evento resiste à eventual desaparição do edifício, como mostram as discussões sobre o sítio de Vel 
d'Hiv, a comemoração da rendição de Von Scholtitz na Estação Montparnasse. Nesses casos, a existência do edifício se desloca para o modo verbal. A menção ao edifício, conservado ou não, é um instrumento da nomenclatura histórica do evento. De um modo um pouco diverso, podemos tratar do edifício ou sítio instrumento de rituais simbólicos; alguns desapareceram: as praças reais, vestígios monumentais da encenação da informação dos súditos na sociedade do Antigo Regime (10); outros são as marcas virtuais que certos eventos deixaram na crônica, como os funerais de Vítor Hugo, da Étoile ao Panteão, a ocupação do Odéon em 1968, a cerimônia fúnebre no pátio do Louvre em honra a Le Corbusier, e a homenagem de Mitterrand no Panteão, em maio de 1981

A representação do evento, fixada num edifício comemorativo específico. O monumento comemorativo intencional fixa um lugar simbólico, distinto da localização dos eventos aos quais se refere. Pode ser portador da memória de um ou mais eventos: no mesmo local, o Arco do Triunfo da Étoile em Paris é sucessivamente o monumento comemorativo dos exércitos napoleônicos e o monumento em Memória da Segunda Grande Guerra, simbolizada pelo Túmulo do Soldado Desconhecido; os monumentos aos mortos, em particular, são os instrumentos da produção de eventos simbólicos, objeto de representações importantes e renovadas. Em suma, é uma tradição já expressiva em Roma, que é a da monumentalidade histórica, a do edifício, como se diz hoje, devotado a uma finalidade específica. O edifício monumental é, então, o instrumento direto da comemoração do evento (11).

Sua importância na memória coletiva pode ser amplificada quando é um dos motores da monumentalidade urbana das cidades e das capitais: Arco do Triunfo da Étoile em Paris, monumento aos Girondinos em Bordeaux, Trafalgar Square em Londres.

\section{0 edifício, um evento na vida das formas}

Ainda nesse caso, seguimos a divisão em categorias admitidas por Riegl para os monumentos (12). Os edifícios-evento, sob esse ponto de vista, são aqueles que a história da arquitetura como arte conserva e celebra; são, por um lado, os edifíciosmanifesto, que são intencionais e, por outro, as obras pioneiras (por uma ou várias razões) sobre as quais os historiadores afirmam a importância absoluta ou relativa. 
Note-se que a importância dada à representação pelos atores do tribunal da história (da arte) conduz à redução da importância dada à identidade material da obra. Com efeito, constata-se que, uma vez que a obra é inscrita entre as molduras de um museu imaginário, as diferenças da identidade material tendem a se reduzir, a mesclar o edifício temporário e o perene, o edifício realizado e o projeto ou o estudo: sob esse ponto de vista, os manifestos podem tanto ser o estudo para uma Cidade Industrial de Tony Garnier, ou documentos da exposição do plano Voisin ou a vila Savoye de Le Corbusier, reunidos na unidade pela intensidade e abrangência da recepção. Note-se ainda que o reconhecimento do valor histórico-artístico é parcialmente desconectado do valor de uso, numa espécie de desvio que reduz a importância prática e social do edifício-evento. Desse modo, o Museu Guggenheim de Bilbao pode ser apreendido, independentemente de suas virtudes na nova sistematização do sítio e na política urbana, como um evento formal, pelo historiador israelense Elie Barnavi, que considera que o Guggenheim de Bilbao é hoje uma "suntuosa concha vazia" (13), ou seja, cujo conteúdo é fraco, ou mesmo inexistente.

Esse deslocamento da identidade do edifício-evento para sua representação conduz ao questionamento sobre a realidade dos procedimentos e dos benefícios da recepção. Os exemplos abundam. Giulia Mariano estuda o exemplo do edifício construído para a Caisse d'Allocations Familiales (CAF - Fundos de Auxílio à Família) em Paris; esse edifício foi por duas vezes um evento: no momento de sua construção (arq. Lopez, 1953-1959), pois os diferentes atores da recepção invocam o argumento do valor como novidade arquitetônica, urbana e construtiva; no momento de sua desocupação, uma vez que uma vigorosa controvérsia opôs, em 1990, os partidários de sua preservação aos responsáveis pela CAF, que optaram por sua demolição; sob a forma de um evento, tratado como tal pela imprensa, seguiram-se os episódios excepcionais de sua inscrição no ISMH (14), sucedida por uma anulação feita através de ato administrativo de tribunal, confirmada pelo Conselho de Estado.

Qualquer que seja o conjunto de edifícios notáveis, é possível verificar como se conjugam os critérios da opinião pública e os da crítica erudita para definir os edifícios-evento: isso ocorre com o centro universitário de Jussieu, com o Centro Georges Pompidou, com o Arco da Défense, com o viaduto de Calatrava (em 
Orléans). Numa tal acumulação heteróclita, percebe-se a justaposição da recepção local e da recepção abrangente, da fama vulgar e da apreciação dos especialistas, vários círculos concêntricos ao redor do objeto da recepção, instrumento de sua própria representação.

Dessa recepção diversificada resulta que a recepção do edifício como evento histórico-artístico pode responder a critérios temáticos específicos, relativos às novas ramificações da especialização histórica: o evento é tipológico, construtivo, ou programático?

Seria necessário admitir que o edifício-evento é primeiramente um objeto de saberes, antes que esses saberes alimentem o julgamento e a recepção. Donde a constatação de perdas e lacunas: quando os saberes não estão suficientemente constituídos, nem suficientemente difundidos, o reconhecimento do edifício-evento pode estar ausente ou, se permanecermos otimistas no que respeita à difusão dos saberes, defasado. Eis que posso mencionar ainda uma vez o não-reconhecimento do evento tipológico que constitui a Universidade de Brasília (1960-1962, arq. O. Niemeyer).

\section{0 edifício, instrumento de eventos culturais}

De modo completamente independente da noção monumental, sem, no entanto, excluí-la, o edifício destinado a ser o instrumento do evento cultural contínuo ou em série constitui uma terceira categoria de edifícios-instrumentos do evento. Nela se encontram tanto monumentos históricos adaptados à produção de espetáculos (Palácio dos Papas em Avignon, já mencionado, teatro antigo de Orange), quanto edifícios cujo programa é relacionado a eventos, como os pavilhões de exposições universais. Responde exatamente a essa definição o prédio construído no Parque do Ibirapuera para a celebração dos 400 anos da fundação de São Paulo (1951-1954, que se tornou o local da Bienal de Arte de São Paulo, arq. O. Niemeyer). A apresentação de uma coleção de obras de arte contemporânea num edifício histórico tem o valor de evento: os museus Picasso em edifícios históricos em Antibes e em Paris, a coleção de mármores antigos do Capitólio na Central Termoelétrica de Montemartini, na via Ostiense em Roma, a Coleção do Museu de Artes Aplicadas de Roubaix numa piscina municipal (15). 
Historicamente, essa categoria tem sua fonte em todas as formas de espetáculo ao vivo, teatro, competições esportivas, apresentações de circo. Essa fonte antiga está na origem da tradição em casos como a tauromaquia, em praças antigas ou modernas, e espetáculos circenses, apresentados sob uma cobertura fixa ou móvel. Se admitirmos que hoje a indústria do espetáculo, que se tornou indústria do entretenimento, transforma o espectador em consumidor de cultura e que a necessidade de renovação dos produtos impõe a renovação do evento-chamariz, o edifício ad hoc para cada um desses lugares de produção da indústria do entretenimento está destinado a ser o instrumento do evento: um evento que deve impor-se no espaço social, face à concorrência dos instrumentos tecnológicos do consumo cultural em domicílio. Essa oferta concerne ao conjunto dos edifícios especializados que são os instrumentos da produção do evento concreto, hipódromos, salas de concerto, estádios, teatros etc. Note-se que num período recente, a concepção arquitetônica da sala de concertos - desde a de Scharoun (em Berlin) até a de Piano (em Roma) - assimila o edifício a um instrumento na produção de um concerto e, portanto, a um lugar matricial para a difusão das gravações.

Hoje, os teatros, casas de ópera, auditórios, centros de convenção, estádios, piscinas são os lugares de manifestações disciplinares que são objeto de uma comunicação intensa, que ultrapassa os objetivos econômicos da própria atividade, que fixa a identidade do edifício e que possui uma função política. Com efeito, essa comunicação é não apenas proporcional ao seu papel social, mas é também necessária para justificar o investimento dos políticos e das administrações, assim como dos orçamentos, tanto para o setor público quanto para o setor privado, na produção e na gestão do equipamento. A cultura e o esporte, organizados segundo a lógica do espetáculo e de sua economia, têm um peso na relação das instituições com os equipamentos e a infra-estrutura.

A atualidade mostra-nos que os próprios museus se tornam lugares de eventos (16). De início, quando são confundidos com o evento: o dia da abertura ao público de um novo museu; depois, através de eventos como uma exposição temporária, a apresentação de uma nova aquisição, a conferência de um especialista, a visita de um chefe de Estado estrangeiro, a realização de um concerto integrado e de todas 
as espécies de manifestações provocadas pela influência de especialistas da comunicação sobre a programação. O Grand Palais, cuja reabertura foi um evento, ilustra a freqüência da renovação das manifestações atraentes, tantos eventos para os quais o edifício é concomitantemente o instrumento e a aura. Hoje ele é objeto de disputa para localizar, abrigar, produzir manifestações (Feira de Antiquários, Feira do Livro etc); é assim decisivo o prestígio do edifício, produto da acumulação de eventos e de sua restauração, da valorização de sua arquitetura e de sua situação na centralidade urbana. Esses valores maiores levam à minoração das lacunas no conforto e no valor de uso.

Entre os edifícios públicos recentes, a separação entre os equipamentos que estão ligados à produção do evento e os outros se torna, por conseguinte, pertinente. Assim, nos dois pólos dessa separação, encontram-se os estádios, instrumentos do esporte-espetáculo, e as bibliotecas, lugares com uso de intensidade constante ao abrigo, na maior parte do tempo, de qualquer evento.

As disciplinas da cultura e do esporte, organizadas segundo e lógica do espetáculo e de sua economia, pesam na relação das instituições com os equipamentos e a infraestrutura. Em 1980, um relatório oficial, Les bibliothèques en France [As bibliotecas na França], assim se manifestava:

O Ministério da Cultura, constituído em 1959, é antes de tudo [...] um Ministério das Artes Plásticas e dos Espetáculos, através das estruturas privilegiadas que são as grandes obras: grandes teatros, grandes museus, Centros Culturais, Centro Georges Pompidou, que são ainda instituições-chave: o espaço cultural que pivilegia esse Ministério é o do evento; tratase, portanto, de inserir menos em suas prioridades políticas, com um orçamento baixo, aquilo que resulta da prática cultural individual quotidiana, da vida das instituições médias espalhadas por todo o território, de inovações sem projeção. (17)

Nessa categoria, a produção do evento varia, em quantidade e em intensidade, de maneira substantiva: os usos polivalentes do Ginásio Omnisports de Paris-Bercy asseguram a esse edifício um lugar na produção de eventos intensos, múltiplos e freqüentes, enquanto no Estádio Charlety os eventos são exceção (note-se que o famoso encontro político de junho de 1968 foi realizado no antigo estádio, hoje desaparecido; o estádio atual, notoriamente sub-utilizado, apesar de sua arquitetura 
excepcional, não contribuiu, até o presente momento, para fixar um evento de maior importância).

Para os teatros, casas de ópera, auditórios, centro de convenções, estádios, piscinas, notamos que as manifestações disciplinares concernidas são objeto de uma intensa comunicação que ultrapassa os objetivos econômicos da atividade. Essa comunicação é proporcional ao seu papel social, mas é também necessária para justificar o investimento dos políticos e das administrações, para o setor público e também para o setor privado, na produção e na gestão do equipamento. O Teatro dos Campos Elíseos desde o início de seu funcionamento, levou a confundir, ao que parece, seu valor como edifício de vanguarda, com o valor de ruptura dos espetáculos de que é instrumento, sendo os famosos Balés Russos os mais conhecidos.

Essa relação entre o evento e o edifício resulta em efeitos consideráveis. Quando o edifício, que é a sede de eventos culturais, possui uma forte identidade arquitetônica, esta última não resiste à importância das manifestações que o edifício abriga quando essas manifestações se repetem com intensidade.

Esse foi o caso do Grand Palais, com a sucessão de grandes "salões" populares, Salão do Automóvel, Salão de Utilidades Domésticas, cuja freqüentação, para cada um deles, ultrapassava em muito o milhão de visitantes. O Salão de Utilidades Domésticas nos anos 1950 obtinha um sucesso que estava à altura da avidez de um público que ali encontrava, com as promessas futuras do consumo de massa, o antídoto para a longa penúria do pós-guerra (18). Durante o Salão do Automóvel, nos anos 1950-1960, o interesse pela construção se esvaecia completamente diante do valor como novidade dos produtos expostos, que eram o evento da vez. Não se pode imaginar, hoje, a intensidade do que foi a descoberta pelo público do Renault 4 cavalos-vapor, do Citroën 2cv, do DS 19, modelos cuja revelação, ao fim de um processo de segredo industrial bem guardado, tinha por enquadramento passivo as naves do Grand Palais. À descoberta pelo público se sucedia, nas horas que se seguiam, a cobertura feita pela imprensa escrita e pelos jornais cinematográficos. Uma vez que manifestações com a mesma intensidade se sucediam no mesmo enquadramento (ao Salão do Automóvel, no outono, sucedia-se, na primavera, o 
Salão de Utilidades Domésticas), ocorria um fenômeno de renovação do público.

Essa questão da relação entre 0 evento e $\circ$ edifício tem efeitos culturais significativos. Pode levar, de fato, a um enfraquecimento da recepção da identidade arquitetônica e a um desvanecimento de seu valor próprio; isso se passa hoje com o Ginásio Omnisports de Paris-Bercy (Palais Omnisports de Paris-Bercy - POPB 1980-1983, Andrault e Parat arq.). O Ginásio, que tem capacidade para 18 mil espectadores, é o instrumento da produção de eventos e de espetáculos intensos, múltiplos e freqüentes, que vão desde o espetáculo esportivo até o teatro, passando pelo one man show de cantores-estrela, convenções políticas etc. A gama de esportes representada é extensa, vai do futebol ao ciclismo (os Seis Dias de Paris, de 1984 a 1989), ao boxe, ao atletismo (campeonatos europeus in door em $1994 \mathrm{e}$ 1997), ao hockey sobre o gelo. Com o POPB, tudo se passa como se a atração das manifestações sucessivas, pela sua intensidade própria assim como pelas suas diferenças, levasse a um esvaecimento completo do interesse pelo edifício, pela sua eficácia como instrumento que se adapta à variedade das produções, pelas configurações da sala adaptadas ao espetáculo; tudo aquilo que no funcionamento desse edifício provém do desempenho técnico e da eficácia da gestão é objeto de uma total sub-representação, como se a renovação de seu dispositivo físico, uma vez reconhecida, recaísse na banalidade dos trens que chegam na hora. Ademais, o sucesso popular dos conteúdos e sua difusão pela mídia se dão sem nenhum reconhecimento pelo valor arquitetônico de um edifício do qual não se menciona jamais o nome dos arquitetos e raramente o pioneirismo na metamorfose histórica da paisagem do leste parisiense. Ora, foi nesse edifício que se realizou pela primeira vez um dos objetivos seculares do racionalismo e do funcionalismo (19): liberar a concepção de um grande edifício da tirania da mono-função e da mera disponibilidade de espaço, que ainda é o programa tanto do CNIT (20) como do Centro Georges Pompidou. Apenas um acidente grave, com mortes, parece capaz de integrar um edifício-instrumento do evento ao reconhecimento material concreto; foi possível constatar isso, em 5 de maio de 1992, com o desabamento da tribuna do Estádio de Furiani, construída por ocasião de um evento do esporte-espetáculo, a semifinal da Copa da França de Futebol; balanço do acidente: 18 mortos e 2.357 feridos. Foram as conseqüências judiciais que, a seguir, concentraram a atenção nas técnicas de construção, na empresa e em seus responsáveis. 
Essa ausência de reconhecimento do desempenho técnico num programa complexo de edifício-instrumento do evento é um desafio. Mídia e políticos poderiam questionar-se sobre o potencial de economia de investimentos, de espaço e de energia que possui essa abordagem de uma arquitetura tecnológica capaz de responder, de modo concomitante, a objetivos de desenvolvimento sustentável, e de propor o retorno a uma gestão mais centrada do espaço urbano.

\section{Conclusão}

Os edifícios, em suas relações com o evento, foram durante muito tempo instrumentos da representação simbólica e suportes da informação. O rápido desenvolvimento da indústria do entretenimento abre um novo capítulo: o edifício pode tornar-se engrenagem principal de uma máquina de divertir através de eventos, um instrumento cujo desempenho e gestão mobilizam fatores novos no espaço e no tempo: isso ocorre com as controvérsias recentes sobre a localização de novas salas de cinema e, do mesmo modo, com a reserva antecipada (com meses de antecedência) de lugares para concertos e espetáculos das estrelas do showbiz etc.

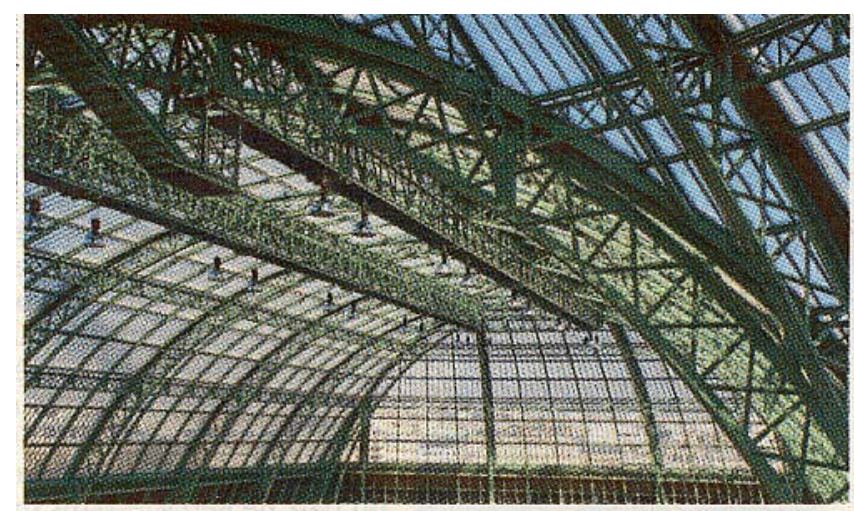

Il aura fallu deux semaines pour lessiver les $13500 \mathrm{~m}^{2}$ de verrière.

FIGURA 1 - O evento: a limpeza dos vidros do Grand Palais. Fonte: Métro, 20 de fevereiro de 2008 
FIGURA 2 - O calendário dos "eventos futuros" no Grand Palais. Fonte: Métro, 20 de fevereiro de 2008.

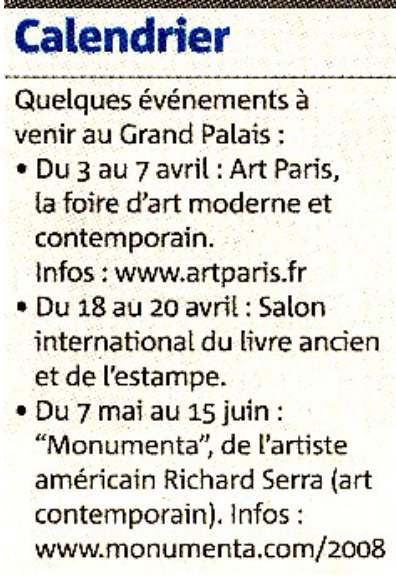

\section{Le Cirque du Soleil en "délire" à Bercy}

\author{
SPECTACLE. La célèbre troupe \\ du Cirque du Soleil s'instal- \\ le au Palais omnisports de \\ Paris-Bercy du 30 mars au \\ 3 avril pour offrir son \\ spectacle haut en couleur : \\ Delirium. Les artistes propo- \\ seront un "événement-per- \\ formance" reliant \\ étroitement les univers \\ visuels et sonores. \\ Créé et mis en scène par les \\ concepteurs scénographes \\ Michel Lemieux et Victor \\ Pilon, Delirium a la particu- \\ larité de mélanger des per- \\ formances acrobatiques sin-
}

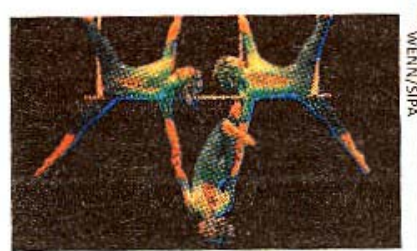

gulières. Le spectacle, qui mêle danse et théâtre, offrira des numéros de danse acrobatique, d'acrosport et d'équilibre sur canne, le tout accompagné de musique, de projections sur toiles géantes et d'inserts multimédias. RELAXNEWS "Tarif : de 4.1 aे 75 e.
FIGURA 3 - Anúncio de um "evento
performance" (sic) no POBP. Fonte: Métro, 20 de fevereiro de 2008.

\section{Notas}

(1) O presente texto foi escrito originalmente em francês para a revista Contemporanéité et temporalité, Cahiers Thématiques $n^{\circ} 8-2008$, Ecole nationale supérieure d'architecture et de paysage, Lille, p. 15-23 (no prelo).N. da T.

(2) A palavra événement em francês é utilizada tanto com o sentido de um evento de interesse (espetáculo, exposição etc.), que mobiliza os meios de comunicação e atrai o público, quanto de acontecimento histórico. Em português, evento e acontecimento são palavras empregadas freqüentemente como sinônimos, mas em alguns casos (como ao se tratar de fatos históricos) é mais comum o uso do vocábulo acontecimento. Dado o tema do artigo, optou-se, nesta tradução, por usar sempre a palavra evento. N. da T.

(3) Este artigo dá continuidade a temas tratados anteriormente pelo autor em: MONNIER, Gérard. O edifícioevento e a história contemporânea, Desígnio, São Paulo, n. 6, p. 11-18, 2006. No artigo o autor esboça uma análise da tipologia do edifício-evento no campo da história da arquitetura contemporânea, separando o edifício- 
evento fortuito (como no caso de destruição do edifício, que pode ser acidental ou provir da guerra) do edifícioevento programado (que pode ser subdividido em várias categorias). A partir desse inventário tipológico primário, o autor esboça algumas tarefas a serem empreendidas pelo historiador: "documentar a produção e a difusão de informação de que o edifício-evento é objeto, interrogando-se sobre sua extensão no espaço e no tempo - até onde, durante quanto tempo, como e por que se difunde a informação sobre o evento? Quem são os atores? Que contribuição durável isso traz à recepção?". A partir desse questionamento, o autor elabora duas hipóteses, que desenvolve no decorrer do artigo: "na primeira, o edifício-evento é um obstáculo ao conhecimento histórico e à construção da narrativa histórica; na segunda, o edifício-evento, fundamentalmente associado à modernidade, ao próprio proceder dos atores, à sua autenticidade, deve ser objeto de uma aproximação abrangente por parte do historiador." N. da T.

(4) FOCILLON, Henri. La vie des formes. 3 ed. (1 ed. 1934). Paris, 1947. p. 95.

(5) Ver o notável estudo de: LOYER, Emmanuelle; BAECQUE, Antoine de. Histoire du Festival d'Avignon. Paris: Gallimard, 2007.

(6) O Juramento do Jeu de Paume, ocorreu em 20 de junho de 1789, na sala do Jeu de Paume no palácio de Versalhes, feito pelos deputados do Terceiro-Estado durante a realização dos Estados Gerais (Assembléia Nacional): eles juraram não dissolver a reunião até que fosse elaborada uma Constituição. N. da T.

(7) Em 16 de julho de 1942, deu-se início, em Paris, à prisão e deportação de mais de 12 mil judeus, franceses e estrangeiros, através de operação conduzida pela polícia francesa sob ordens dos ocupantes alemães. N. da T.

(8) Em 8 de fevereiro de 1962, incitada por organizações de esquerda francesas, foi convocada uma manifestação em prol da paz na Argélia. A manifestação foi proibida pelo poder público, que mandou reprimi-la resultando em 9 mortes. N. da T.

(9) Ou monumento não intencional (das ungewollte Denkmal), para retomar as categorias de Alois Riegl (1903). RIEGL, Alois. Le culte moderne des monuments. Paris: Le Seuil, 1984. p. 43.

(10) Cf sobre esse tema: FOGEL M. Les cérémonies de l'information dans la France du XVI ème au XVIII ème siècle. Paris: Fayard, 1989.

(11) Cf nosso estudo L'architecture monumentale contemporaine, une question d'histoire? Histoire de l'art, n. 27 , p. 7-17, 1994.

(12) Riegl identificava o "monumento da história da arte" (das Kunsthistorische Denkmal). RIEGL, A., op. cit., p. 39.

(13) Segundo as palavras do historiador israelense Elie Barnavi, encarregado do Museu da Europa em Bruxellas, registradas por Emmanuel de Roux et Jean-Pierre Stroobants por ocasião da exposição 'C'est notre histoire' [É a nossa História], Le Monde, 3 de janeiro de 2008.

(14) Inventaire Supplémentaire des Monuments Historiques [Inventário suplementar de Monumentos Históricos]. A inscrição nessa lista de inventário tem implicações legais semelhantes ao do tombamento no Brasil. N. da T. 
(15) A piscina municipal de Roubaix (1927-1932) foi construída pelo arquiteto Albert Baert (1863-1951). Foi fechada em 1985 e transformada em museu (1994-2001) pelo arquiteto Jean-Paul Philippon.

(16) Ver o dossiê apresentado em Le Débat, Le moment du Quai Branly, n. 147, nov./dez. 2007.

(17) Apud Hélène Caroux, em sua obra a ser publicada pelas Editions Picard, Architecture et lecture. Les bibliothèques municipales en France 1945-2002.

(18) Cf LEYMONERIE, Claire. Le Salon des Arts ménagers dans les années 1950. Théâtre d'une conversion à la consommation de masse. XXo siècle, Revue d'Histoire, n. 91, p. 43-56, 2006.

(19) Foi a escolha que guiou a concepção da Maison du Peuple - mercado coberto de Clichy (1936-1939, E. Beaudouin et M. Lods arquitetos, W. Bodiansky, engenheiros)

(20) Centre National des Industries et Techniques [Centro Nacional das Indústrias e Técnicas], cuja construção foi iniciada em 1956 com projeto de Robert Camelot, Jean de Mailly e Bernard Zehrfuss. Entre 1987 e 1989 passa por grande modernização comandada pelos arquitetos Michel Andrault, Pierre Parat, Ennio Torrieri et Bernard Lamy, contando com Zerhfuss como consultor. Trata-se de um enorme complexo para congressos e exposições, contando com hotel, escritórios, centro comercial e de serviços, restaurante com c. de 43 mil m². N. da T.

\section{Crédito}

* Professor emérito da Université de Paris I Panthéon-Sorbonne.

Tradução: Beatriz Mugayar Kühl - Arquiteta. Livre Docente pela FAU-USP. Docente do Departamento de História da Arquitetura e Estética do Projeto da FAU-USP.

Título original: L'édifice, instrument de l'événement: une problématique. 